\title{
Modelo de lectura profesional para la indización de textos científicos
}

\author{
Mariângela Spotti Lopes Fujita \\ Milena Polsinelli Rubi \\ Universidade Estadual Paulista de Marília (Brasil)
}

\section{Resumen}

Se propone un modelo de lectura profesional orientado a la indización de documentos científicos que se apoya en dos metodologías complementarias: un esquema de preguntas básicas - los pronombres quién, qué, cómo, cuándo y dóndey la identificación de las partes de la estructura textual de los documentos que contienen las respuestas para un tipo documental dado. Se parte del análisis de los fundamentos teóricos y metodológicos obtenidos de la literatura previa: principalmente procedente de los campos de los estudios textuales y las metodologías de indización. Seguidamente, se sintetiza el modelo, y se ofrecen ejemplos de su aplicación. Por último, se presenta el procedimiento de validación y corrección del modelo, realizado a partir del estudio de los protocolos verbales que los indizadores de la Subred Nacional de Información en Ciencias de la Salud (BIREME) y del Centro de Informaciones Nucleares produjeron durante el uso de la metodología. En apéndice, se ofrece un manual para la formación de indizadores, tanto en el nivel de grado como en el de posgrado.

Palabras clave: Lectura profesional. Indización. Metodologías. Modelos.

\section{Abstract}

A model of professional reading oriented to the indexing of scientific documents is proposed. The model is based in two complementary methodologies: a scheme of basic questions - the pronouns who, what, how, when and where- and the identification of the parts of the textual structure that contain those answers for a given documentary type. First, relevant previous literature is analyzed to determine the model theoretical and methodological foundations, mainly in the field of textual studies and indexing methodologies. Next, the model is synthesized from this background, and examples of their application are offered. Finally, the procedure of validation and correction of the model is described, which was based on the study of the verbal protocols that the indexers of the National Network of Health Sciences Information (BIREME) and the Nuclear Information Center pro-

Scire. $12: 1$ (en.-jun. 2006) 47-69. ISSN 1135-3761. 
duced during their use of the methodology. In appendix, a manual for the training of indexers is offered, both for graduate and postgraduate level.

Keywords: Professional reading. Indexing. Methodology. Models.

\section{Introducción}

$\mathrm{El}$ indizador es un lector que interacciona con el texto para cumplir el objetivo de la indización; en esa interacción, el indizador lee el texto. Partiendo de esta simple constatación, el estudio del proceso de lectura del indizador ofrece una nueva perspectiva para la comprensión de los problemas a los que este se enfrenta durante el proceso de indización de un documento. En concreto, la observación del proceso de lectura del indizador permitirá comprobar las estrategias de comprensión que actúan en la identificación de conceptos y de su contexto, y verificar los aspectos que influyen y determinan la lectura documental en cuanto que lectura profesional.

$\mathrm{Al}$ igual que cualquier otro lector, el indizador tiene que interaccionar a distancia con las ideas de un autor; pero, además, el indizador es también un lector profesional. Como lector normal, debe ser considerado bajo la perspectiva de la psicología cognitiva, pues, al leer, acciona, como cualquier otro individuo, el procesamiento humano de la información, realizado con la memoria a corto plazo (input visual) y a largo plazo (esquemas y conocimiento previo), y el conjunto de habilidades operativas del pensamiento (análisis y síntesis). Por otra parte, como lector profesional, debe ser considerado a partir de variables más específicas: su contexto, formación y actuación profesional, así como desde los propios objetivos de la indización. Así pues, el indizador es, por un lado, un lector con conocimientos previos de tipo lingüístico, textual, generalista y profesional; y, además, en el caso de los indizadores especialistas, también específicos de su materia.

Por tanto, el proceso de análisis temático de un documento con la finalidad de indizarlo implica la comprensión del texto mediante procesos cognitivos, realizados a partir de esquemas mentales. Puesto que esos esquemas de conocimiento previo implícito no se suelen enseñar, la conciencia de que existen e influyen en los resultados y objetivos de la lectura documental marca la diferencia clave en el desempeño del lector-indizador, por lo menos en lo que se refiere a su disposición a ser evaluado y a asumir cambios. De esa manera, el objetivo principal de la formación del indizador y del resumidor debería ser formarle y capacitarle para una lectura con objetivos profesionales, tomando conciencia de sus habilidades cognitivas, tanto innatas como adquiridas.

Las dificultades existirán porque la lectura es un proceso de interacción con el texto escrito que pretende su comprensión y eso supone un proceso de cognición. Kleiman (2000, p. 7) plantea el problema de manera simple y clara: “¿Podemos enseñar la comprensión? ¿Podemos enseñar un proceso cognitivo? Evidentemente, 
no. El papel del profesor, en ese contexto, es crear oportunidades que permitan el desarrollo de ese proceso, siendo que esas oportunidades podrán ser mejor creadas a medida en que el proceso sea mejor conocido". En cualquier caso, conocer el proceso de la lectura documental y las variables que influyen en ella es una misión primordial para que los responsables de la formación y capacitación del indizador puedan crear recursos teóricos y metodológicos que redunden en el perfeccionamiento y mejora de la enseñanza de la indización.

Una de las principales preocupaciones de los investigadores en indización es la rápida evolución de las técnicas de recuperación automática, que conllevan el aumento de la responsabilidad del indizador en la determinación del tema del documento. Las nuevas formas de recuperación le exigen una mayor profundización teórica para evitar el riesgo de una práctica descomprometida con la representación del contexto del documento y del sistema de recuperación de la información. Cunha (2000, p. 71) expresa bien esta transformación al enunciar que "La sustitución de los paradigmas tradicionales de las profesiones de la información como consecuencia del impacto de las nuevas tecnologías sobre el procesamiento, la transmisión, la organización y el acceso a la información, la ubicuidad de la información disponible y su acceso virtual, todo contribuye para repensar competencias, habilidades y estrategias de formación para un ejercicio profesional satisfactorio". En ese sentido, tanto los cursos de graduación en Biblioteconomía como los orientados a la educación continua del profesional indizador tienen una gran responsabilidad en su formación y capacitación para la lectura documental.

La formación del profesional bibliotecario como indizador necesita de aportes teórico-metodológicos específicos sobre lectura documental —incluyendo sus aspectos cognitivos y lingüísticos-, que se deberían proporcionar dentro del área curricular de Organización de la Información de los cursos de Biblioteconomía. Creemos que los estudios sobre lectura pueden mejorar el desempeño de indizadores y el uso de metodologías de indización. Con esta formación, además, el futuro indizador podrá estar más capacitado no solo para el desempeño de su actividad, sino para su propio autodesarrollo.

Para la investigación en lectura documental —y considerando que el concepto de lectura y su influencia en la actuación profesional todavía carecen de estudios metodológicos que identifiquen las sistemáticas más apropiadas de análisis temático para la identificación de los conceptos en los textos científicos-, propusimos la elaboración de un modelo de lectura a partir, principalmente, de los resultados del estudio de observación de las estrategias de lectura documental del indizador realizado por Fujita (2003), que buscaba fundamentar teórica y metodológicamente la lectura profesional del indizador en el sentido indicado. El modelo se basa en dos estrategias complementarias: primero, la exploración de las estructuras textuales y, posteriormente, el abordaje sistemático de la identificación de conceptos. El moScire. $12: 1$ (en.-jun. 2006) 47-69. ISSN 1135-3761. 
delo terminado fue aplicado experimentalmente, y, posteriormente, evaluado y corregido según los resultados y conclusiones obtenidos.

\section{Estrategias del indizador en la lectura documental: observación y análisis}

Los resultados conseguidos en el estudio antedicho demostraron que los indizadores no utilizaban a la vez las dos estrategias mencionadas, y constituyeron el germen que ha culminado en la elaboración de un modelo de lectura documental para textos científicos. Dicho modelo parte del análisis del indizador desde una perspectiva cognitiva y lingüística en cuanto que lector, y observa su lectura documental, constatando tanto la utilización de las estrategias metacognitivas de carácter general preconizadas por los teóricos de la lectura como la de las estrategias específicas del análisis temático para la indización. La dificultades de análisis temático se analizan a partir de la influencia de las tres variables que actúan durante el proceso de lectura; a saber: texto, lector y contexto.

A partir de la visión interacionista del proceso de lectura, se estudia cómo el indizador aborda sus dificultades en la identificación de conceptos durante el análisis temático, y se muestran los factores que influyen en su lectura y lo convierten en un lector profesional: sus objetivos de indización, su actuación y formación profesional, y sus concepciones de la lectura.

Para estudiar al indizador como un agente que practica la lectura con fines específicos - concretamente, el examen del documento y la identificación de conceptos-, se utilizó el método introspectivo del "protocolo verbal" o "pensar en voz alta" (Fujita, Nardi, Fagundes, 2003). Se contó con la colaboración de dos importantes instituciones documentales. Por una parte, el Centro Coordinador Nacional del Sistema Especializado en el Área de Odontología del Centro Latinoamericano y del Caribe de Información en Ciencias de Salud (BIREME) de la Organización Panamericana de la Salud (OPAS) — www.bireme.br- facilitó la participación de cuatro indizadores bibliotecarios a través del Servicio de Documentación en Odontología de la Biblioteca de la Facultad de Odontología de Universidad de São Paulo. Por otra parte, el Centro de Informaciones Nucleares de la Comisión Nacional de Energía Nuclear (CIN/CNEM), del International Nuclear Information System (INIS) — www.cnen.gov.br—, facilitó la participación de cuatro indizadores expertos.

Las transcripciones de los protocolos verbales de los ocho indizadores se sometieron a dos análisis sucesivos. El primer análisis de los protocolos verbales mostró la correlación positiva entre el uso de estrategias metacognitivas y la comprensión del documento por parte de los indizadores. Se constató también que el indizador se beneficia del conocimiento previo — lingüístico, textual y generalis- 
ta - que ha adquirido a lo largo de su vida. Los resultados del segundo análisis demuestran la utilización de estrategias de análisis propias de lectura documental, y proporcionan observaciones importantes para la mejora de su formación profesional de grado, y posteriormente continua, tanto dentro como fuera del contexto de trabajo. De esa manera, la lectura en análisis documental es entendida como un actividad de carácter profesional que caracteriza al indizador como un lector profesional que realiza la lectura documental dentro de su contexto profesional.

En el análisis de la variable texto, cuya estructura sirve de soporte a la comprensión, se constató la necesidad tanto de un conocimiento lingüístico como del dominio de la estructura textual por parte del indizador. De hecho, la exploración de esta última ha sido identificada como una estrategia de lectura documental que le ayuda en la identificación y selección de conceptos durante el análisis temático. Efectivamente, la principal estrategia observada en los protocolos verbales ha sido la identificación de conceptos, cuyo accionamiento y sistemática dependieron del uso de la estrategia de exploración de la estructura textual. La constatación de que los indizadores combinan ambas estrategias por medio de una metodología formal de lectura documental es una importante demostración de los beneficios que pueden resultar del uso de la metodología observacional en el estudio de la lectura del indizador. Por otro lado, se ha observado también que los indizadores no utilizan durante la lectura un abordaje sistemático de identificación de conceptos como el que propone la norma 12.676 (Asociación Brasileña de Normas Técnicas, 1992), esto es, un esquema de cuestionamiento del texto cuyas respuestas permiten identificar los términos representativos de los conceptos formulados. Finalmente, el testimonio de los indizadores observados permite constatar también la dificultad que tienen para identificar los conceptos en el análisis temático.

Un aspecto muy importante que el estudio ha revelado son las diferencias en las estrategias y desempeño de los indizadores profesionales, por un lado, y los expertos temáticos, por el otro. Los resultados comparativos de la lectura de los indizadores bibliotecarios y de los expertos demuestran que estos últimos —a pesar de dominar mejor el tema, realizan una lectura más cognitiva (y, por lo tanto, comprensiva), y utilizan su conocimiento previo de la estructura textual del mismo modo que los bibliotecarios - no dominan procedimientos sistemáticos en el abordaje del contenido textual para la identificación de conceptos de forma que exista una correlación entre los conceptos identificados (acción, objeto de acción, actividad o proceso, agente de acción, procedimientos, materiales, etc.) y su localización en partes específicas del texto (introducción, metodología, resultados y conclusiones). Suponemos que el indizador especialista, que domina el tema, realiza la lectura conceptual con movimientos de lectura descendentes (top-down), porque utiliza más estrategias cognitivas y menos estrategias metacognitivas. Durante la lectura conceptual, no usa la referencia a los términos en lenguaje natural

Scire. $12: 1$ (en.-jun. 2006) 47-69. ISSN 1135-3761. 
para la identificación y selección de conceptos, sino la compatibilidad de los términos seleccionados con el lenguaje del sistema de indizador.

Por su parte, se puede comprobar que el indizador no-experto realiza también una lectura conceptual, dada la gran cantidad de estrategias metacognitivas realizadas para monitorizar la comprensión. Realiza un gran esfuerzo de comprensión y, por falta de dominio del tema, su conocimiento de referencia es el lenguaje documental del sistema. La comprensión del texto resultó ser evidentemente menor que la del indizador especialista, aunque se constató la existencia de una lectura conceptual.

Se constató, también, que la exploración de la estructura textual y de los indicadores perceptibles de los componentes textuales fue realizada de manera similar por los indizadores expertos y no expertos, lo que demuestra que se trata de un conocimiento previo y necesario. Igualmente, se evidencia que uno de los componentes textuales más utilizados para la identificación de conceptos fue la introducción, que contiene generalmente el objetivo del trabajo, posibilitando, así, la identificación el tema.

La falta de un procedimiento sistemático para la identificación de conceptos, tanto por parte de los expertos en el área científica como de los no expertos, es un resultado importante del estudio, pues esta identificación es un punto clave de la lectura del indizador y depende de estrategias que faciliten la comprensión. En el caso del experto, esa estrategia puede ser sustituida por el conocimiento del tema; pero, para el no experto, constituye un facilitador importante que aumenta la comprensión de lectura.

Considerando que la identificación de conceptos es un objetivo de la lectura documental y la operación más importante de la indización, los resultados obtenidos nos llevan a concluir que la identificación de conceptos depende de la destreza del indizador en la exploración de la estructura textual, pues durante la lectura es necesario tener en mente la correlación entre los conceptos que se buscan y los términos que les corresponden en partes específicas del texto.

La observación más concluyente es que los indizadores - fueran bibliotecarios o expertos - no demostraron un dominio de los procedimientos sistemáticos para el abordaje del contenido textual de cara a la identificación de conceptos. Esta comprobación invitaba a considerar la posibilidad del uso combinado de la exploración de la estructura textual con el cuestionamiento para la identificación de conceptos, para facilitar una lectura documental más rápida y estratégica desde el punto de vista profesional. De ahí surgió la idea de elaborar un modelo de lectura que facilitara al lector el reconocimiento de las estructuras textuales y, apoyándose en estrategias sistemáticas de identificación de conceptos, sirviera para acelerar su comprensión y facilitar una lectura más rápida, consiguiendo, en definitiva, que el indizador desarrollase una lectura más estratégica que el lector normal. 
A continuación se presenta la síntesis teórica en la que se basa el antedicho modelo de lectura. Posteriormente, se describe el proceso seguido para su construcción, así como una discusión crítica de su aplicabilidad.

\section{Metodología para elaboración del modelo de lectura}

Como se ha visto anteriormente, los resultados de la observación de la lectura documental demostraron que los indizadores bibliotecarios y expertos carecían de procedimientos sistemáticos para la identificación de los conceptos del contenido textual. Como consecuencia, se planteó la posibilidad de usar combinadamente, por un lado, la exploración de la estructura textual y, por el otro, un cuestionario para la identificación de conceptos, con la finalidad de realizar una lectura documental más rápida y estratégica desde el punto de vista profesional. Así pues, la metodología de elaboración del modelo de lectura se concentró en la combinación de ambos aspectos.

Para concretar la propuesta del modelo, se realizó un estudio de la literatura previa que se orientó, por un lado, a los fundamentos teóricos de los estudios sobre estructuras textuales, y, por el otro, a verificar la existencia de propuestas metodológicas que combinaran el análisis de la estructura textual y la identificación de conceptos, ya fuera mediante metodologías de análisis conceptual, ya utilizando procedimientos de abordaje sistemático.

\subsection{Estructura textual e identificación de conceptos: propuestas metodológicas}

El conocimiento de las teorías sobre las estructuras textuales es fundamental para fundamentar de manera rigurosa la elaboración de un modelo de lectura para la indización. El conocimiento textual es parte del conocimiento previo del lector y es una de la condiciones para que se produzca la comprensión lectora (Fujita, 1999; Kleiman, 2000). De acuerdo con Koch (2002, p. 17), en la concepción interaccional de la lengua, el texto es el lugar de la interación cuando se tiene, junto al sujeto lector, el contexto sociocognitivo de los participantes de la interación. En esta concepción, Koch (2002, p. 20) comparte y subscribe la definición propuesta por Beaugrande (1997, p. 10) para texto: "evento comunicativo en el cual convergen acciones lingüísticas, cognitivas y sociales". Y es que el texto, además de una estructura lingüística, posee una estructura de significado que únicamente "aparece" cuando el lector hace una lectura comprensiva. Por tanto, el texto está sujeto también a una interpretación cognitiva y no solo lingüístico-descriptiva. Dado el fuerte componente cognitivo de la lectura, cuanta más habilidad y más familiaridad posee el lector con las tipologías y estructuras textuales más facilidad tendrá para comprender (Kato, 1986; Cintra, 1987; Kobashi, 1994).

Con respeto a la estructura del texto, se afirma que se relaciona con la manera en la cual las ideas están organizadas en él en función del contenido, el tema y 
los conceptos tratados. Como la estructura del texto se articula en función de su contenido, el autor de un texto elige una determinada estructura textual que venga a coincidir con el contenido que quiere transmitir. Por eso, una parte importante del proceso de comprensión de lectura es justamente la habilidad para reconocer el género y los diferentes tipos de estructuras textuales. Ese conocimiento teórico ayuda al lector en la necesaria identificación de la idea principal o el tema del texto.

La idea principal varía de acuerdo con la estructura textual; por ejemplo, en un texto narrativo esta idea puede ser un acontecimiento o su interpretación, mientras que en un texto informativo puede ser una regla, un concepto o una generalización. Cuando la idea principal aparece implícita, el lector debe inferirla a partir de las informaciones proporcionadas por el texto y de su conocimiento previo sobre el tema. Así, por ejemplo, en el caso de los textos técnico-científicos, Tálamo (1987) sitúa la identificación del tema en el reconocimiento del "objetivo" del trabajo. Un hito importante para la identificación del tema es el cuestionamiento sistemático por las categorías temáticas: ¿qué? (categoría esencial), ¿cuándo?, ¿dónde?, ¿cómo? (categorías accesorias). A esta estrategia podemos denominarla de inferencia, y se la puede considerar como un elemento fundamental de los modelos de lectura para la indización.

Para Kobashi (1994), la extracción de información documental para producir resúmenes e índices puede ser eficiente si el indizador conoce la superestructura textual, o sea, la manera en que un texto está organizado, pues, en cuanto que paradigma de organización textual, el esquema o superestructura provee una base para la interpretación. Y es que el texto, según Van Dijk (1992, p. 142), está compuesto de superestructura y macroestructura. La superestructura es un tipo de forma del texto cuyo objeto - el tema- es el contenido del texto. Un tema puede ser desarrollado de varias maneras. Lo que distingue una de otra son los diferentes tipos de construcción.

No existe una teoría general de las superestructuras, sino de determinadas superestructuras, particularmente la narración y la argumentación. Por esa razón, en las investigaciones realizadas hasta el momento, Van Dijk (1992) no ofrece una teoría general de la estructura textual, sino que se limita a proporcionar una serie de observaciones sobre las hipotéticas características de esas estructuras. Este estudio se centra en la estructura de los textos científicos, ya que las observaciones del proceso de lectura han sido realizadas a partir de estudios de caso de servicios de análisis de literatura científica. El texto científico deriva, según Van Dijk (1992), de una estructura argumentativa compuesta de justificación y conclusión, sumadas a la presentación del problema y su solución.

El texto científico tiene, siguiendo a Kobashi (1994, pp. 114-116) una estructura compuesta de seis partes: a) el tema a desarrollar; b) el problema —-dificultad que se quiere solucionar científicamente—; c) la hipótesis — proposición que 
propone una respuesta a un problema anticipándose a la comprobación de una realidad y que podrá ser comprobada o rechazada a partir de las observaciones a las que se sometan los hechos-; d) la metodología — conjunto de procedimientos y operaciones que posibilitan la observación racional y controlada de los hechos, de manera que permitan la interpretación y la explicación adecuada del fenómeno observado; e) el resultado — que implica la aceptación, rechazo o reformulación de las hipótesis—; y f) la conclusión — comentario final, que discute las posibilidades de aplicación y de utilización de los resultados, es decir, la incorporación o no de estos últimos a un sistema teórico.

A partir de los presupuestos teóricos sobre la estructura textual fue posible utilizar el esquema de comprensión literal de discursos científicos de Tálamo (1994) y la metodología de indización de textos científicos de Kobashi (1994) para fundamentar la elaboración del modelo de lectura de textos científicos en lo que concierne a sus aspectos operacionales.

La metodología de indización propuesta por Kobashi (1994) se orienta a identificar el tema de los documentos utilizando la metodología de Tálamo (1987) que consiste en identificar el tema de un documento por medio de un mecanismo de preguntas y repuestas. Para Tálamo (1987), el tema se designa como un conjunto de indicaciones agrupadas por generalidades que responden a cada una de las siguientes cuestiones fundamentales: quién (ser), qué (tema), cómo (modo), dónde (lugar) y cuándo (tiempo). Por su parte, la metodología propuesta por Kobashi (1994) para la indización consiste en identificar el tema por medio de la lectura del documento, confirmar si el tema del texto es también su objetivo y elaborar el enunciado temático por medio de los mecanismos de respuesta. El modelo relatado se limita a la aplicación de la metodología de indización solo con los textos científicos que presentan dicha estructura - problema, hipótesis, metodología, resultados y conclusiones- L La metodología consiste, en primer lugar, en identificar el tema y confirmar si el mismo constituye también el objetivo del texto. En segundo lugar, se procede al desmontaje del texto, buscando evidenciar las partes de su estructura textual —objetivo, introducción, problema, hipótesis, metodología, resultados y conclusiones-, así como las líneas en las que se encuentran esos elementos en el texto. Ese desmontaje es realizado a partir de la identificación de la superestructura del texto, indicando con mayor objetividad cuál es el tema tratado en el texto y evitando que se produzcan equívocos. En tercer lugar, se procede a realizar la indización del texto teniendo en cuenta el objetivo del texto encontrado durante la primera etapa, y respondiendo, si es posible, a las preguntas qué (tema), cuándo (tiempo), dónde (lugar) y cómo (modo). Kobashi (1994) se basa en el mecanismo de preguntas conceptuales de Lasswell (1971) — who, what, when, where, why-, utilizadas también por García Gutiérrez y Lucas (1987). Desde este punto de vista, el tema posee una estructura semántica compuesta por conceptos o categorías o 
facetas, cuya identificación resulta del análisis conceptual del documento. La síntesis de las categorías identificadas formula el tema del documento en cuestión.

Según Kobashi (1994), se deben señalar dos precisiones importantes al respecto de esta metodología de indización. En primer lugar, resalta que se han utilizado solo cuatro categorías en la operación de identificación del tema —a saber: qué, cuándo, dónde y cómo-, a pesar de que la propuesta de Tálamo comprende cinco categorías. Esto se debe a que se ha observado, empíricamente, que la categoría quién - caracterizada por el trazo "humano"- parece no tener apenas importancia en los textos de naturaleza técnico-científica, aunque sea, por otra parte, esencial en los narrativos y en las noticias periodísticas. En segundo lugar, constata que la categoría "qué" es esencial, por ser el elemento nuclear de la estructura temática, mientras que las restantes categorías — cuándo, dónde, cómo- se agregan de manera accesoria al núcleo temático — pueden o no estar presentes en un texto-, sin que se pueda determinar ningún tipo de orden de precedencia entre ellas.

El análisis del esquema de comprensión literal de discursos científicos (Tálamo, 1994) y el de la metodología de indización de textos científicos (Kobashi, 1994) muestra que han sido propuestos a partir de la exploración del conocimiento del indizador y del resumidor sobre la organización de la estructura textual. La metodología de Kobashi (1994) va un poco más allá, porque insiste en la búsqueda del tema y utiliza para la identificación de conceptos estrategias de inferencia del contenido. Al estar orientada a la práctica, describe de manera bastante explícita las reglas y la metodología propuestas y, como resultado, permite alcanzar al indizador y al resumidor una lectura comprensiva, eficiente y, sobre todo, selectiva. Así pues, a efectos de valorar su viabilidad, se constata que el modelo de Kobashi (1994) resulta de fácil aplicación, y además combina la exploración de la estructura textual con la encuesta como abordaje sistemático para la identificación de conceptos de indización.

\subsection{Identificación de conceptos en lectura documental: abordaje sistemático y análisis conceptual}

El abordaje sistemático, según se ha podido apreciar en las metodologías de Tálamo y Kobashi, es de hecho un cuestionamiento que el indizador realiza para extraer mejor los conceptos mientras realiza la lectura documental del texto; y la consideramos de fundamental importancia, porque se revela como una estrategia de inferencia que orienta al indizador en la identificación de los conceptos. Por ello, no es extraño que el cuestionamento como abordaje sistemático se proponga también en las normas documentales. La norma 12.676 de la Asociación Brasileña de Normas Técnicas (1992), traducción de la norma ISO 5693 de 1985, define el aprendizaje de la identificación de conceptos como "un abordaje sistemático para identificar aquellos conceptos que son elementos esenciales en la descripción del

Scire. $12: 1$ (en.-jun. 2006) 47-69. ISSN 1135-3761. 
tema", y recomienda una encuesta del texto mediante un conjunto de cuestiones diseñadas para identificar determinados conceptos esenciales: ¿Posee el documento en su contexto un objeto bajo el efecto de una actividad? ¿Contiene el tema un concepto activo como, por ejemplo, una acción, una operación o un proceso? ¿Es influenciado el objeto por la actividad identificada? ¿Posee el documento un agente que practicó esta acción? ¿Utiliza este agente procedimientos específicos para realizar la acción como, por ejemplo, instrumentos especiales, técnicas o métodos? ¿Están situados estos factores en un lugar o ambiente específico? ¿Se pueden identificar variables dependientes? ¿Se considera el tema desde un punto de vista normalmente no asociado con el campo de estudio, como, por ejemplo, un estudio sociológico o religioso?

La comprensión operativa de la encuesta supone considerar que cada cuestión permite la identificación de su concepto correspondiente. La primera cuestión, por ejemplo, debe permitir identificar en el texto la presencia del concepto objeto; la segunda, acción; la tercera, si el objeto identificado sufre influencia de la acción; la cuarta, el agente que practicó la acción; y así sucesivamente. Trabajando alrededor de estos conceptos universales, el sistema PRECIS recomienda, para la etapa de identificación de conceptos del análisis temático, un análisis conceptual basado en la interrogación del texto en el que a cada cuestión le corresponde un concepto con una función característica dentro del tema: ¿qué ocurrió? (acción); ¿a quién o a qué ocurrió? (objeto de la acción o sistema clave); ¿qué o quién hizo esto? (agente de la acción); ¿dónde ocurrió? (localización)... Una vez identificados, los conceptos se estructuran en un enunciado temático cuyo mensaje deberá representar el resultado del último análisis, una idea global del texto que facilite la comprensión del lector. Este procedimiento de identificación de conceptos indicado por la norma 12.676 y por el análisis conceptual del PRECIS puede ser observado a partir del siguiente texto de ejemplo y de la identificación de sus conceptos y subsiguiente enunciado del tema (tabla I).

Se puede suponer, mientras tanto, que el abordaje sistemático y el análisis conceptual son maneras de preguntarse que el indizador utiliza como estrategias de inferencia para extraer mejor los conceptos mientras va leyendo las distintas partes del texto, puesto que la norma 12.676 y el análisis conceptual de PRECIS no explicitan qué cuestiones son las más indicadas para cada parte del texto. La cuestión de dónde localizar los conceptos depende de la identificación de la estructura temática. Así, o bien el tema está formulado de manera clara en el objetivo del trabajo, conforme recomiendan tanto el esquema de comprensión literal de discursos científicos de Tálamo (1994) como la metodología para indización de textos científicos de Kobashi (1994); o bien, cuando esto no ocurra, será necesaria la localización específica de los conceptos dentro de la estructura del documento conforme a su estructura textual. En este último caso, el modelo de lectura tendrá, 


\section{Comparación de la economía minera y azucarera}

Si bien el promedio de la economía minera estaba por debajo del que conociera la región del azúcar, su mercado presentaba potencialidades mucho mayores. Sus dimensiones absolutas eran superiores, pues las importaciones representaban una menor proporción del dispendio total. Por otro lado $-\mathrm{y}$ esto constituye el aspecto principal del problema - la renta estaba mucho menos concentrada, ya que la proporción de la población libre era mucho menor. La estructura del mercado tenía que ser necesariamente diversa, ocupando los bienes de consumo corrientes un espacio mucho más significativo que, por el contrario, los artículos de lujo. Además, la población, aunque dispersa en un gran territorio, estaba en gran parte reunida en núcleos urbanos y semi-urbanos. Por último, la gran distancia existente entre la región minera y los puertos contribuía a encarecer relativamente los artículos importados. Este conjunto de circunstancias convertía a la región minera en un espacio mucho más propicio para el desarrollo de actividades relacionadas con el mercado interno del que había sido hasta el momento la región azucarera. Por el contrario, el desarrollo endógeno —es decir, con base en su propio mercado- de la región minera fue prácticamente nulo. Es fácil comprender que la actividad minoritaria absorbiera todos los recursos disponibles en la etapa inicial. Es menos fácil explicar, sin embargo, que, una vez establecidos los centros urbanos, no se desarrollaran suficientemente las actividades manufactureras de grado inferior, las cuales habrían podido expandirse en la etapa subsiguiente de dificultades de importación. Se ha buscado explicación para ese hecho en la política portuguesa, una de cuyas preocupaciones era dificultar el desarrollo manufacturero de la colonia. Mientras, el decreto de 1.785 que prohibía cualquier actividad manufacturera no parece que suscitara gran reacción, siendo más o menos evidente que el desarrollo manufacturero había sido prácticamente nulo en todo período anterior de prosperidad y decadencia de la economía minera. La causa principal posiblemente fue la propia incapacidad técnica de los inmigrantes para iniciar actividades manufactureras en una escala ponderable.

Teixeira, Francisco M. P.; Dantas, J. Historia de Brasil de la colonia a la república. 2. São Paulo: Moderna, 1979. 141. Furtado, Celso. Formación Económica de Brasil. São Paulo: Fondo de Cultura, 1965. 98-99.

\section{Cuadro I. Texto analizado}

\begin{tabular}{|l|l|l|}
\hline Tipo de concepto & Pregunta & Respuesta \\
\hline Acción & ¿Qué sucedió? & Análisis de la economía \\
\hline Objeto de la acción & $\begin{array}{l}\text { ¿A qué le sucedió? o ¿qué tipo } \\
\text { de economía? }\end{array}$ & Mercado interno \\
\hline Parte del objeto de la acción & ¿De qué? & Actividades manufactureras \\
\hline Tiempo/fecha & ¿Cuándo? & Período colonial \\
\hline Localización geográfica & ¿Dónde? & Minas Gerais, Brasil \\
\hline $\begin{array}{l}\text { Enunciado del tema: Análisis de la economía de las actividades manufactureras del mercado interno } \\
\text { de Minas Gerais en Brasil durante el período colonial }\end{array}$ \\
\hline
\end{tabular}

Tabla I. Identificación de conceptos y enunciado del tema

Scire. $12: 1$ (en.-jun. 2006) 47-69. ISSN 1135-3761. 
además, una especificación sobre la localización de los conceptos en las correspondientes partes de la estructura textual.

\section{Modelo de lectura para la indización de textos científicos}

En resumen, la investigación de presupuestos teóricos ofreció como modelos relevantes, por un lado, tanto las teorías de la estructura textual como la existencia de tres propuestas metodológicas que combinan la estructura textual y la identificación de conceptos. En concreto: el esquema de comprensión literal de discursos científicos de Tálamo (1994); la metodología para indización de textos científicos de Kobashi (1994); y la localización de la estructura temática en partes del texto. Por otro lado, el estudio indicó también dos metodologías de análisis conceptual y abordaje sistemático para la identificación sistemática de conceptos: el análisis conceptual de PRECIS (Fujita, 1995) y el abordaje sistemático para identificación de conceptos propuesto en la norma brasileña 12.676 (1992).

Como resultado, en la tabla II se presenta el modelo de lectura obtenido, que tiene por objetivo, fundamentalmente, la combinación de las sistemáticas de identificación de conceptos —el análisis conceptual (primera columna) y el abordaje sistemático de la norma 12.676 (segunda columna) — con la localización de los conceptos en partes de la estructura textual (tercera columna), siguiendo las indicaciones de Tálamo (1987) y Kobashi (1994).

\begin{tabular}{|l|l|l|}
\hline $\begin{array}{l}\text { Concepto } \\
\text { (análisis } \\
\text { conceptual) }\end{array}$ & \multicolumn{1}{l}{ Cuestionamento (norma 12.676) } & $\begin{array}{l}\text { Parte de la estructura } \\
\text { textual (Tálamo, 1987; } \\
\text { Kobashi, 1994) }\end{array}$ \\
\hline Objeto & $\begin{array}{l}\text { ¿Posee el documento en su contexto un objeto bajo } \\
\text { el efecto de una actividad? }\end{array}$ & Introducción (objetivos) \\
\hline Acción & $\begin{array}{l}\text { ¿Contiene el tema un concepto activo como, por ejemplo, } \\
\text { una acción, una operación o un proceso? }\end{array}$ & Introducción (objetivos) \\
\hline Función & ¿Está influenciado el objeto por la actividad identificada? & Introducción (objetivos) \\
\hline Agente & ¿Posee el documento un agente que practicó esta acción? & Introducción (objetivos) \\
\hline $\begin{array}{l}\text { Métodos } \\
\text { del agente }\end{array}$ & $\begin{array}{l}\text { ¿Utiliza este agente procedimientos específicos } \\
\text { para realizar la acción como, por ejemplo, instrumentos } \\
\text { especiales, técnicas o métodos? }\end{array}$ & Metodología \\
\hline $\begin{array}{l}\text { Local o calidad } \\
\text { de ambiente }\end{array}$ & $\begin{array}{l}\text { ¿Están situados estos factores en un lugar } \\
\text { o ambiente específico? }\end{array}$ & Metodología \\
\hline $\begin{array}{l}\text { Causa y efecto } \\
\text { ¿Se pueden identificar variables dependientes? }\end{array}$ & $\begin{array}{l}\text { Resultados; discusión } \\
\text { de resultados }\end{array}$ \\
\hline $\begin{array}{l}\text { Punto de } \\
\text { vista del autor; } \\
\text { perspectiva }\end{array}$ & $\begin{array}{l}\text { ¿Se considera el tema desde un punto de vista } \\
\text { normalmente no asociado con el campo de estudio, } \\
\text { como, por ejemplo, un estudio sociológico o religioso? }\end{array}$ & Conclusiones \\
\hline
\end{tabular}

Tabla II. Modelo de lectura documental para textos científicos: identificación de conceptos mediante preguntas en partes de la estructura textual

Scire. $12: 1$ (en.-jun. 2006) 47-69. ISSN 1135-3761. 
Como ejemplo del uso del modelo de lectura, se presenta en la tabla III un caso resuelto realizado a partir de un artículo de revista científica del área médica. Obsérvese que han sido añadidas dos columnas más a la derecha: la cuarta presenta los términos que representan los conceptos de la primera columna en lenguaje natural, y la quinta columna expresa su traducción al lenguaje documental DeCS, adoptado por BIREME. La tabla III incluye una síntesis, que denominamos enunciado de tema, que revela el tema del documento. Ese enunciado de tema se compone, en orden lógico, uniendo los términos que representan los conceptos identificados.

Para facilitar la utilización del modelo se ha redactado un manual explicativo que contiene los procedimientos de uso y que se presenta en el apéndice 1. Está pensado para ser utilizado por los docentes tanto en la formación inicial de indizadores en los cursos de graduación como para la formación avanzada en los másteres. Consta de una parte introductoria en la que se explica la lectura documental y su objetivo - que es la identificación y selección de conceptos-y de tres partes explicativas, dedicadas a cada uno de los procedimientos principales: exploración del conocimiento de la estructura textual, identificación de los conceptos y selección de los mismos.

Para la adecuación de la versión final del modelo de lectura documental de textos científicos en el manual explicativo se realizaron comprobaciones experimentales con sujetos debidamente orientados mediante protocolos verbales transcritos y analizados (Fujita y Rubi, 2001). La verificación experimental del modelo constó de dos etapas: en la primera — pre-test— se utilizó una versión inicial del manual; en la segunda, se usó la versión modificada del manual conforme a la evaluación de los resultados del pre-test, considerada la versión final. En la fase de pretest, el modelo fue aplicado con alumnos de graduación de Biblioteconomía de la UNESP-Marília, en cinco etapas: indización libre con grabación del protocolo verbal; explicación de la instrucción de lectura; ensayo con el texto; aplicación del método con grabación del protocolo verbal; y declaración sobre la instrucción de lectura. Según los sujetos, la primera versión del manual era, por un lado, muy prolija en explicaciones teóricas que dificultaban el entendimiento de la importancia de la indización y, por el otro, excesivamente concisa en las explicaciones sobre su aplicación práctica, de tal manera que no eran suficientes para su comprensión, especialmente las referidas a la etapa de identificación de conceptos por medio del cuestionario. Presentaba también ambigüedades y problemas de interpretación en las preguntas, dificultando la identificación de los conceptos realmente pertinentes para la indización.

El manual se modificó de acuerdo al análisis realizado de las transcripciones, y a las dificultades encontradas por los sujetos y las informaciones dadas por ellos. Los conceptos del análisis conceptual fueron desarrollados con definiciones y 


\begin{tabular}{|c|c|c|c|c|}
\hline $\begin{array}{l}\text { Tipo de } \\
\text { concepto }\end{array}$ & Preguntas & $\begin{array}{l}\text { Partes de la } \\
\text { estructura } \\
\text { textual }\end{array}$ & $\begin{array}{l}\text { Términos } \\
\text { identificados }\end{array}$ & DECS \\
\hline Objeto & $\begin{array}{l}\text { ¿Posee el documento en su } \\
\text { contexto un objeto bajo el } \\
\text { efecto de una actividad? }\end{array}$ & $\begin{array}{l}\text { Introducción } \\
\text { (objetivos) }\end{array}$ & Recién nacido & Recién nacido \\
\hline Acción & $\begin{array}{l}\text { ¿Contiene el tema un } \\
\text { concepto activo como, por } \\
\text { ejemplo, una acción, una } \\
\text { operación o un proceso? }\end{array}$ & $\begin{array}{l}\text { Introducción } \\
\text { (objetivos) }\end{array}$ & $\begin{array}{l}\text { Colonización } \\
\text { intestinal }\end{array}$ & Colonización \\
\hline Función & $\begin{array}{l}\text { ¿Está influenciado el objeto } \\
\text { por la actividad identificada? }\end{array}$ & $\begin{array}{l}\text { Introducción } \\
\text { (objetivos) }\end{array}$ & & Sí \\
\hline Agente & $\begin{array}{l}\text { ¿Posee el documento } \\
\text { un agente que practicó } \\
\text { esta acción? }\end{array}$ & $\begin{array}{l}\text { Introducción } \\
\text { (objetivos) }\end{array}$ & $\begin{array}{l}\text { Gérmenes } \\
\text { multirresistentes a } \\
\text { antimicrobianos }\end{array}$ & $\begin{array}{l}\text { Enterobacterias } \\
\text { USE } \\
\text { Enterobacteriaceae }\end{array}$ \\
\hline $\begin{array}{l}\text { Métodos } \\
\text { del agente }\end{array}$ & $\begin{array}{l}\text { ¿Utiliza este agente } \\
\text { procedimientos específicos } \\
\text { para realizar la acción como, } \\
\text { por ejemplo, instrumentos } \\
\text { especiales, técnicas } \\
\text { o métodos? }\end{array}$ & Metodología & $\begin{array}{l}\text { Identificación } \\
\text { bacteriana: tests } \\
\text { de sensibilidad a } \\
\text { los antimicrobianos: } \\
\text { muestras fecales; } \\
\text { extracción de DNA } \\
\text { plasmidial } \\
\text { bacterian; } \\
\text { electroforesis en } \\
\text { gel de agarosa }\end{array}$ & $\begin{array}{l}\text { No tiene prueba } \\
\text { de sensibilidad } \\
\text { bacteriana } \\
\text { USE prueba } \\
\text { de sensibilidad } \\
\text { microbiana } \\
\text { Heces } \\
\text { DNA bacteriano, } \\
\text { USE eletrosforesis } \\
\text { en gel agar }\end{array}$ \\
\hline $\begin{array}{l}\text { Local o } \\
\text { calidad de } \\
\text { ambiente }\end{array}$ & $\begin{array}{l}\text { ¿Están situados estos } \\
\text { factores en un lugar } \\
\text { o ambiente específico? }\end{array}$ & Metodología & $\begin{array}{l}\text { Cunas del } \\
\text { HUPE-UERJ } \\
\text { Hospital público }\end{array}$ & $\begin{array}{l}\text { Cunas hospitalarias; } \\
\text { hospitales públicos }\end{array}$ \\
\hline $\begin{array}{l}\text { Causa } \\
\text { y efecto }\end{array}$ & $\begin{array}{l}\text { ¿Se pueden identificar } \\
\text { variables dependientes? }\end{array}$ & $\begin{array}{l}\text { Resultados: } \\
\text { discusión de } \\
\text { resultados }\end{array}$ & $\begin{array}{l}\text { Klebsiella } \\
\text { pneumoniae. Bajo } \\
\text { peso. Alimentación } \\
\text { con leche artificial. } \\
\text { Hospitalización. } \\
\text { Uso de } \\
\text { antimicrobianos }\end{array}$ & $\begin{array}{l}\text { Klebsiella } \\
\text { pneumoniae }\end{array}$ \\
\hline $\begin{array}{l}\text { Punto } \\
\text { de vista } \\
\text { del autor; } \\
\text { perspectiva }\end{array}$ & $\begin{array}{l}\text { ¿Se considera el tema desde } \\
\text { un punto de vista normalmente } \\
\text { no asociado con el campo } \\
\text { de estudio, como, por ejemplo, } \\
\text { un estudio sociológico } \\
\text { o religioso? }\end{array}$ & Conclusiones & & \\
\hline \multicolumn{5}{|c|}{$\begin{array}{l}\text { Fuente: Viera, L. A., et al. Colonización intestinal de recién-natos por enterobacterias multirresistentes } \\
\text { a antimicrobianos en unidad neonatal. // Periódico de Pediatría. 75:2 (mar.-abr. 1999) 83-90. } \\
\text { Enunciado de tema: Colonización intestinal de recién-nacidos por gérmenes multirresistentes a } \\
\text { antimicrobianos mediante identificación bacteriana, pruebas de sensibilidad a los antimicrobianos, } \\
\text { muestras fecales, extracción de DNA plasmidial bacteriano y electroforesis en gel de agarosa en } \\
\text { cunas del HUPE-UERJ, cuyas causas fueron la infección por Klebsiella pneumoniae y bajo peso, que } \\
\text { resultó en la alimentación con leche artifical, hospitalización y uso de antimicrobianos. }\end{array}$} \\
\hline
\end{tabular}

Tabla III. Ejemplo de aplicación del modelo de lectura para textos científicos

Scire. $12: 1$ (en.-jun. 2006) 47-69. ISSN 1135-3761. 
ejemplos en el apartado $a$ de la parte II (apéndice). Para facilitar la comprensión de la estructura textual y los conceptos correspondientes, se elaboró el cuadro 1 (apéndice), donde se explican las partes del texto, el contenido pertinente a cada parte y los conceptos que pueden hallarse en cada contenido. El cuestionario se acompaña de un ejemplo resuelto, y las preguntas fueron reformuladas a fin de eliminar las ambigüedades y posibles errores de comprensión. Finalmente, la selección de términos fue incluida como cuarta etapa, a partir de la identificación de conceptos de la etapa anterior.

Esas modificaciones facilitaron considerablemente la comprensión y aplicación del modelo. La versión final del manual explicativo del modelo fue sometida a una nueva prueba aplicada para alumnos de graduación (2) y posgrado stricto (1) y lato sensu (1) de la Unesp-Marília.

Los sujetos consideraron completa la primera parte del modelo, que se refiere a la estructura textual del artículo y a la localización del contenido pertinente. Afirmaron, también, que el modelo de lectura es fácilmente aplicable a la estructura de artículos científicos. Además, destacaron que el modelo de lectura permite que la indización sea exhaustiva y pertinente, pues el cuestionario abarca los diversos aspectos del tema del texto. Los sujetos también consideraron interesante el cuestionario para la identificación de conceptos y el procedimiento para realizar la exploración de la estructura textual facilitando la identificación de conceptos.

\section{Consideraciones finales}

La lectura documental, con sus características propias, presenta dificultades cuyas causas son, en primer lugar, la falta de procedimientos homologados que guíen la lectura y aseguren la identificación de conceptos; y, en segundo lugar, carencias en el dominio del área temática, asegurado en el caso del experto, pero no del indizador. La constatación de la falta de procedimientos sistemáticos de identificación de conceptos reforzó la convicción de que era necesario desarrollar una metodología de análisis temático para disminuir dificultades durante la lectura documental.

A partir de la observación de sus estrategias y concepciones de lectura del lector profesional, se constató la utilización tanto de estrategias metacognitivas de carácter general como de una en concreto que consideramos específica de la lectura documental: la exploración de la estructura textual. El dominio de la estructura textual por el indizador es parte de sus competencias textuales y actúa como facilitador de la tarea de identificación y selección de conceptos, agilizando el análisis temático y asegurando la uniformidad de procedimientos en la indización. A partir de estas constataciones, se propuso un modelo de lectura para indización de textos científicos basado en la combinación de la exploración de la estructura tex- 
tual con la identificación de conceptos por medio de una encuesta básica. El modelo de lectura documental —elaborado y aplicado- ofrece importantes contribuciones para el trabajo y la formación del indizador, destacando tanto su fundamentación teórica como su apoyatura empírica en los resultados del análisis de los protocolos de los sujetos que participaron en su evaluación experimental.

La principal contribución a la operacionalización del modelo de lectura ha sido la elaboración de un manual con explicaciones detalladas para cada etapa de su realización, con abundantes ejemplos que ilustran su aplicabilidad, para que los indizadores dispongan de un recorrido de la tarea paso a paso. De acuerdo con el manual, la lectura dirigida se divide en tres etapas: exploración de la estructura textual, identificación de conceptos y selección de los mismos. En cada una de estas etapas los procedimientos son esclarecidos uno tras otro, a partir de una preparación conceptual y filosófica en indización basada en los resultados de la investigación, hecha en función de las concepciones de análisis, considerándose que la actitud del indizador, al realizar el análisis de un texto con la finalidad de indizar, está directamente vinculada a la concepción de análisis adquirida durante su formación educacional y a la política del sistema.

La concepción de análisis del indizador es formada por la correcta orientación de la indización mediante comprensión del proceso de lectura documental y de sus estrategias. Consideramos que el manual explicativo abarca didácticamente la identificación de conceptos, juzgando con necesario detalle y suficiente ejemplificación los conceptos y la función de cada uno de ellos en el proceso de indización.

Se concluyó, también, —y así se recogió en la versión final del manual— que es necesario que indizador comprenda la metodología en su totalidad antes de implicarse en su parte central — la identificación de conceptos—; de manera que, antes de realizarla, pueda aplicarla, no en partes como sugiere la versión final, sino como un todo y de una sola vez. La etapa de selección también ha sido desmembrada de la de identificación, puesto que depende no solo del contenido del documento, sino también de las demandas planteadas al sistema de información por sus usuarios.

En definitiva, el modelo de lectura que se presenta es una propuesta de mejora de la metodología de indización a partir de un análisis de los procesos metacognitivos del indizador que, además, puede servir para la formación del indizador en la lectura documental. La divulgación de los resultados de este estudio sobre el proceso de lectura documental entre los responsables por la formación y capacitación del indizador — cursos de graduación y sistemas de análisis de información-contribuirá a resaltar la importancia y la influencia que la lectura ejerce sobre todo el desempeño de la actividad de análisis documental. 


\section{Reconocimientos}

Proyecto Integrado de Investigación realizado con apoyo del Conselho Nacional de Desenvolvimento Científico e Tecnológico (CNPq).

\section{Referencias}

Asociación Brasileña de Normas Técnicas (1992). NBR 12676: Métodos para análisis de documentos, determinación de sus asuntos y selección de términos de indexación. Río de Janeiro: Asociación Brasileña de Normas Técnicas, 1992. 4 p.

Beaugrande, R. (1997). New foundations for a science of text and discourse: cognition, communication and freedom of access to knowledge and society. Norwood: Alex, 1997.

Cintra, A. M. M. (1987). Estrategias de lectura en documentación. // Smitt, J. W. Análisis documentario: el análisis de la síntesis. Brasília: IBICT, 1987. 29-38.

Cunha, M. V. C. (2000). La formación de los profesionales de la información en Francia: comparación con el sistema brasileño. // Valentim, M. L. P. (Org.). El profesional de la información: formación, perfil y actuación profesional. São Paulo: Polis, 2000. 71-90.

Fujita, M. S. L. (1995). La organización del pensamiento a través de la estructuración lógica del conocimiento: una propuesta de aplicación del sistema de indexación PRECIS para análisis y comprensión literal de lectura. Marília: Universidad Estadual Paulista, Facultad de Filosofía y Ciencias, 1995. 236 f. Relato de pesquisa (CNPq).

Fujita, M. S. L. (1999). Lectura em análisis documentaria, 1999. Marília, Universidad Estadual Paulista, Facultad de Filosofía y Ciencias; CNPq, 1999. 123 f. Proyecto integrado de pesquisa, relato parcial.

Fujita, M. S. L. (2003). La lectura documental del indexador: aspectos cognitivos y lingüísticos influyentes en la formación del lector profesional. Marília: UNESP, Facultad de Filosofía y Ciencias, 2003. 321 f. Tesis de libre docencia en Análisis Documental y Lenguajes Documentales Alfabéticos.

Fujita, M. S. L.; Rubi, M. P. (2001). Lectura em análisis documentaria. Marília, Universidad Estadual Paulista, Facultad de Filosofía y Ciencias; CNPq, 2001. 185 f. Proyecto Integrado de Pesquisa, Relato parcial.

Fujita, M. S. L.; Nardi, M. I.A.; Fagundes, S.A. (2003). Observing documentary reading by verbal protocol. // Information Research. 8:4 (jul. 2.003).

URL: <http://www.information.net/ir/8-4/paper155.html>.

García Gutiérrez, A.; Lucas, R. (1987). Documentación autorizada de los medios informativos. Madrid: Paraninfo, 1987.

Kato, M. (1986). En el mundo de la escrita: una perspectiva psicolingüística. São Paulo: Ática, 1986. $144 \mathrm{p}$.

Kleiman, A. (2000). Texto y lector: aspectos cognitivos de la lectura. Campinas: Pontes, 2000. $82 \mathrm{p}$.

Kobashi, N. Y. (1994). La elaboración de informaciones documentarias: en busca de una metodología. São Paulo: Universidad de São Paulo, Escuela de Comunicaciones y Artes, 1994. Tesis de doctorado en Ciencias de la Comunicación.

Koch, I. G. V. (2002). Desvedando os segredos do texto. São Paulo: Cortez, 2002.

Scire. $12: 1$ (en.-jun. 2006) 47-69. ISSN 1135-3761. 
Lasswell, H. D. (1971). La estructura y la función de la comunicación en la sociedad. // Cohn, G. Comunicación e industria cultural. São Paulo: Nacional/EDUSP, 1971.

Tálamo, M. F. G. M. (1987). Elaboración de resúmenes. São Paulo: ECA/USP, 1987. 14 p. (Documento mecanografiado).

Tálamo, M. F. G. M. (1994). La comprensión literal de textos. // Cuadernos de Análisis Documentario. 1 (mayo 1994) 13-22.

Van Dijk, T. A. (1992). La ciencia del texto: una visión interdisciplinaria. Trad. de Sibila Hunzinger. Barcelona: Paidós, 1992. 309 p.

\section{Apéndice: Modelo de lectura para indización: manual explicativo}

La lectura documental, realizada por el indizador en la fase de análisis, tiene por objeto propiciar la "identificación de conceptos" para su posterior representación en índices que satisfagan la demanda del usuario. La indización, bajo el punto de vista de los sistemas de recuperación de información, es reconocida como la parte más importante del análisis documental porque condiciona los resultados de la estrategia de búsqueda. El buen o el mal desempeño en la indización se refleja en la recuperación de la información hecha por medio de índices. Ello nos lleva a considerar que la recuperación de los documentos más pertinentes para una determinada solicitud de búsqueda es aquella cuya indización haya proporcionado previamente la identificación de los conceptos más pertinentes para su contenido, lo que produce una correspondencia precisa con el tema investigado en los índices.

En la identificación de conceptos, el indizador, después del examen del texto, pasa a abordarlo de una manera lógica con el objeto de elegir los conceptos que mejor representan su contenido. Hace falta que la selección de los términos se haga considerando los objetivos conforme a los cuales la información es indizada. De esta guisa, no todos los conceptos identificados serán necesariamente seleccionados.

En el contexto del análisis para la indización, la lectura es la actividad principal, pues, por ser la fase inicial, influenciará el desempeño del resto de las operaciones y resultará en la selección de los términos que representarán el documento para el usuario. Así, la lectura se orienta a los objetivos de la indización, lo que no pasa con aquellas lecturas que se orientan a otros fines.

Teniendo en cuenta que la identificación de conceptos es el objetivo de la lectura documental y la operación más importante de la indización, los resultados obtenidos en anteriores investigaciones (Fujita y Rubi, 1998) llevan a las siguientes conclusiones: a) la identificación de conceptos puede depender de la destreza del indizador en la exploración de la estructura textual; y b) hay dos operaciones distintas realizadas por los indizadores durante la lectura (¡no después de ella!), la identificación de conceptos y la selección de términos. Por ello, estas instrucciones de lectura se componen de tres procedimientos principales: 1) la exploración de la estructura textual, 2) la identificación de conceptos, y 3) la selección de conceptos.

Scire. $12: 1$ (en.-jun. 2006) 47-69. ISSN 1135-3761. 


\section{Exploración de la estructura textual}

1. Observación de la estructura textual: Busque en el texto científico los elementos que lo componen, aunque no estén señalados por ítems o puestos de relieve. Todo texto posee una estructura, en relieve o no, que podemos denominar superestructura. Esa observación debe ser hecha, por lo tanto, basándose en ella, para así apuntar, con más objetividad, cuál es el tema tratado en el texto, evitando, así, que se cometan errores: título en portugués, título en inglés, autoría, resumen del trabajo científico, palabras clave, abstract, keywords, introducción, materiales y métodos, resultados, figuras, discusión de los resultados, conclusiones y referencias bibliográficas.

2. Localización del contenido pertinente de cada una de esas partes del texto. El contenido pertinente a cada parte del texto se estructura en un esquema normalizado, cuyas partes son las siguientes:

- Introducción: explicación del tema principal, su referente teórico y los objetivos de la investigación, estando estos últimos normalmente al final de la introducción.

- Materiales y métodos: descripción de los materiales y métodos — procesos, técnicas, muestreo- utilizados.

- Resultados: en consonancia con los objetivos enunciados, y los materiales y métodos utilizados, frecuentemente se presentan mediante figuras, gráficos, tablas, fotografías, etc.

- Discusión de los resultados: contrastación de los resultados con el referente teórico utilizado.

- Conclusión: comprobación del grado de consecución de los objetivos propuestos.

- Referencias bibliográficas.

(Importante: La realización de la etapa 2 es imprescindible, pues resultará en la comprensión global del texto).

\section{Identificación de conceptos}

La metodología utilizada en esta etapa consiste en la identificación de conceptos, que será realizada combinando la exploración de la estructura textual y el panel de preguntas fundamentales. La identificación de conceptos es la fase principal de la indización, y depende de la comprensión del significado e importancia del concepto. Se entiende por concepto la formulación de una idea mediante palabras.

Así, por ejemplo, el concepto de agente puede ser definido como aquel o aquello que realizó la acción. Ello significa que el concepto agente estará representado en el texto por un término de cuyo contexto dependerá que se le identifique o

Scire. $12: 1$ (en.-jun. 2006) 47-69. ISSN 1135-3761. 
no con la idea de agente. En cualquier caso, se garantiza que los conceptos básicos puedan ser identificados en cualquier texto, lo que asegura que todos los textos sean comprensibles y sus conceptos identificables.

Ejemplo: "Destrucción de plantaciones de café por la helada". El agente en este caso es la helada, pues "practicó" la acción de destrucción de las plantaciones de café.

a) Comprensión de conceptos

Los conceptos esenciales del documento son:

- Objeto: algo o alguien que está bajo estudio del investigador.

- Acción: proceso sufrido por algo o alguien.

- Agente: alguien o algo que realizó la acción.

- Métodos: métodos utilizados para realización de la investigación.

- Local físico o ambiente: local físico donde se ha realizado la investigación.

- Causa y efecto:

- Causa: razón o motivo; alguien o algo que hace con que algo exista u ocurra (antecedente); está vinculada a la identificación de la acción.

- Efecto: producto de una causa; resultado de un acto cualquiera (consecuencia); está vinculado al resultado de la acción realizada.

Así, el presunto efecto o consecuente debe variar cada vez que hace variar la presunta causa o antecedente.

Ejemplo: "Grupos familiares carentes que migran son propensos a la desorganización interna". Causa: proceso de migración. Efecto: desorganización interna del grupo familiar.

b) Identificación de conceptos mediante exploración de la estructura textual

Para lograr un mejor resultado en la identificación de conceptos, tenga en cuenta las partes del texto en las cuales los conceptos suelen, generalmente, localizarse:

\begin{tabular}{|l|l|l|}
\hline Partes del texto & Contenido pertinente & Conceptos \\
\hline $\begin{array}{l}\text { Introducción } \\
\text { (objetivos) }\end{array}$ & $\begin{array}{l}\text { Referencial teórico } \\
\text { Tema* } \\
\text { Objetivos }\end{array}$ & $\begin{array}{l}\text { Objeto } \\
\text { Agente } \\
\text { Acción }\end{array}$ \\
\hline Metodología & Descripción de materiales, métodos, procesos y técnicas utilizados & $\begin{array}{l}\text { Métodos } \\
\text { Local físico } \\
\text { Materiales }\end{array}$ \\
\hline $\begin{array}{l}\text { Resultados } \\
\text { Discusión de } \\
\text { los resultados }\end{array}$ & $\begin{array}{l}\text { Compatibilidad con objetivos enunciados y materiales y métodos } \\
\text { utilizados, presentados a veces en tablas } \\
\text { Comprobación de los resultados a partir del referencial teórico } \\
\text { utilizado }\end{array}$ & $\begin{array}{l}\text { Causa } \\
\text { y efecto }\end{array}$ \\
\hline
\end{tabular}

Tabla I. Identificación de conceptos mediante exploración de la estructura textual (note que el tema, generalmente, se expresa por medio del objetivo)

Scire. $12: 1$ (en.-jun. 2006) 47-69. ISSN 1135-3761. 


\section{c) Cuestionario para la identificación de conceptos del texto}

Por otro lado, este resultado lo obtendrá más fácilmente si utiliza el siguiente cuestionario, pues las respuestas a esas preguntas guían el análisis del documento y resultan en la selección de los términos. A continuación, presentaremos un ejemplo que muestra el uso del cuestionario y la obtención de términos a partir de la identificación de los conceptos obtenidos como respuesta.

Ejemplo: "Proliferación de la flora anaerobia en el intestino delgado en lactantes portadores de diarrea aguda y persistente".

1. ¿Posee el tema una acción (esto es, una operación, un proceso, etc.)?

- Acción: proliferación.

2. ¿Posee el documento en su contexto un objeto que experimenta el efecto de esa acción?

- Objeto: flora anaerobia.

2.1. ¿Puede considerarse el objeto como parte de una totalidad?

- Parte del objeto: "flora anaerobia" es parte del "intestino delgado", que es parte del todo "lactante".

2.2. ¿Posee el objeto características o atributos particulares?

- En el susodicho ejemplo no hay característica o atributo, con todo, en el ejemplo "Sustancia aromática del vino", vino sería el objeto y sustancia aromática el atributo.

3. ¿Posee el documento un agente que ha practicado esa acción?

- Agente: microorganismos anaerobios.

4. ¿Menciona y/o describe el documento modos específicos para el estudio del objeto o implementación de la acción (por ejemplo, instrumentos especiales, técnicas, métodos, materiales y equipamientos)?

- Métodos: intubación intestinal; análisis morfológico de las colonias.

- Materiales.

5. ¿La acción, el objeto y el agente son considerados en el contexto de un lugar específico o ambiente?

- Local físico o ambiente: se ha realizado la investigación en unidades de gastroenterología pediátrica.

6. Si se tiene en cuenta que la acción y el objeto identifican una causa, ¿cuál es el efecto de esta causa?

- Causa: proliferación de la flora anaerobia (acción+objeto).

- Efecto: diarrea aguda y persistente, pues cuando hay aumento de la proliferación de la flora anaerobia empeora la diarrea aguda y persistente.

(Observación: a veces, no todas las preguntas pueden ser contestadas).

Scire. $12: 1$ (en.-jun. 2006) 47-69. ISSN 1135-3761. 
Tras la comprensión del texto en cuestión, identifique los conceptos combinando la exploración de la estructura textual con la encuesta.

\section{Selección de conceptos}

A partir de la identificación de conceptos que ha realizado por medio de las respuestas al cuestionario, seleccione los conceptos que considera importantes para una representación más pertinente del contenido del documento y que asegure en términos del lenguaje documental adoptado el respeto a la garantía de uso del documento.

Ejemplo:

\begin{tabular}{|l|l|}
\hline Términos identificados & Términos seleccionados \\
\hline Flora anaerobia & Flora anaerobia \\
\hline Proliferación & Proliferación de la flora anaerobia \\
\hline Microorganismos anaerobios & Microorganismos anaerobios \\
\hline Intubación intestinal & \\
\hline Análisis morfológico de las colonias & Análisis morfológico \\
\hline Unidades de gastroenterología pediátrica & \\
\hline Proliferación de la flora anaerobia & \\
\hline Diarrea aguda y persistente & $\begin{array}{l}\text { Diarrea aguda } \\
\text { Diarrea persistente }\end{array}$ \\
\hline
\end{tabular}

Tabla II. Identificación y selección de términos (versión final modificada) 